\title{
ANALISIS IMPLEMENTASI PELAYANAN PADA PENYELENGGARAAN DIKLAT DI PPSDMA (Studi Kasus Pada Diklat Teknis Pelaksana I Tahun 2018 di Bandung dan Cisolok)
}

\author{
Ganjar Hermadi \\ Pusat Pengembangan sumber Daya Manusia Aparatur \\ Email: ganjar.hermadi@esdm.go.id
}

\begin{abstract}
ABSTRAK
Implementasi pelayanan, khususnya pada pelayanan diklat belum berjalan secara optimal. Terlebih jika penyelenggaraan diklat dilaksanakan didua lokasi yang berbeda Bandung dan Cisolok. Tujuan penelitian ini adalah menganalisa implementasi pelayanan diklat pada Diklat Teknis Pelaksana I (TP I) pada 2018 di Bandung dan Cisolok, Sukabumi. Metode penelitian menggunakan pendekatan deskriptif kualitatif berdasarkan pengamatan penulis sebagai salah satu pengajar pada diklat tersebut dan analisis data hasil evaluasi penyelenggaraan diklat serta wawancara. Informan penelitian adalah salah satu petugas di bidang penyelenggaraan diklat yang terlibat pada Diklat TP I. Hasil yang diharapkan dari penelitian ini adalah rekomendasi untuk pelaksanaan Diklat TP I yang lebih baik di masa depan dan penyelenggaraan diklat di PPSDMA secara umum. Hasil lain yang diharapkan adalah penelitian ini bisa menjadi referensi untuk pelaksanaan pelatihan yang lebih optimal sesuai dengan pelayanan yang berlaku di PPSDMA.
\end{abstract}

Kata Kunci: pelayanan, penyelenggaraan diklat, Diklat Teknis Pelaksana I

\section{ABSTRACT}

Implementation of services, especially in education and training services has not run optimally. Especially if the training is held in two different locations, Bandung and Cisolok. The purpose of this study is to analyze the implementation of education and training services in Diklat Teknis Pelaksana I (TP I) in 2018 held in Bandung and Cisolok, Sukabumi. The research method uses a qualitative descriptive approach based on the author's observations as one of the instructors in the training and analysis of the results of the evaluation of the training implementation and an interview. The informant is the one of the training officer that involved at Diklat TP I. The expected results of the study are recommendations for better implementation of Diklat TP I in the future and the implementation of education and training in the PPSDMA in general. The other expected results of this study is to be a reference for the implementation of training that is more optimal in accordance with the services applicable in PPSDMA.

Keywords: services, training organizer, Diklat Teknis Pelaksana I

\section{PENDAHULUAN}

Berdasarkan pengamatan awal penulis sebagai salah satu pengajar pada Diklat Teknis Pelaksana I yang dilaksanakan didua lokasi berbeda, yaitu Bandung dan Cisolok, terdapat perbedaan sikap penerimaan peserta diklat. Perbedaan tersebut tercermin pada lembar evaluasi pemantauan penyelenggaraan diklat yang dilakukan oleh bidang evaluasi. Perbedaan ini bisa berdampak kepada rendahnya penilaian pelayanan diklat yang diselenggarakan oleh Pusat Pengembangan Sumber Daya Manusia Aparatur (PPSDMA) yang mempunyai komitmen untuk memberikan pelayanan terbaik dalam bidang penyelenggaraaan diklat.

Diklat TP I adalah diklat yang diamanatkan untuk diselenggarakan oleh PPSDMA sebagai
Diklat Teknis Substantif Pengelola secara berjenjang mengacu kepada Peraturan Menteri ESDM No. 34 Tahun 2016 tentang Diklat Teknis Bagi PNS Bidang ESDM. Diklat TP I ini adalah pelatihan yang diperuntukkan bagi PNS baru (new hired), yaitu PNS yang baru bergabung dengan KESDM, yang telah lulus pelatihan Calon PNS/ Prajabatan. Tujuan dari Diklat TP I ini adalah peserta diklat mampu mengidentifikasi kegiatan bidang ESDM, yang meliputi bidang geologi, migas, mineral batubara serta ketenagalistrikan dan energi baru terbarukan. Sehingga PNS yang baru tersebut diharapkan lebih mengenal KESDM secara keseluruhan dan mengetahui kegiatan bidang apa saja yang ditangani oleh Kementerian. Latar belakang yang mendasari pelaksanaan Diklat TP I didua lokasi yang berbeda pada tahun 
2018 adalah adanya target yang harus dicapai oleh PPSDMA dalam hal pelaksanaan Diklat TP I sebanyak lima belas diklat dengan jumlah peserta pelatihan PNS sebanyak 500 orang. Pelaksanaan Diklat TP I didua lokasi tersebut tentunya mempunyai nilai positif dan negatif. Nilai positifnya adalah target organisasi tercapai, sedangkan negatifnya adalah biaya operasional menjadi membengkak dan fokus manajemen dalam menyelenggarakan diklat menjadi terbagi sehingga bisa berimbas kepada pelayanan diklat.

Penelitian ini bertujuan menganalisis implementasi pelayanan kediklatan pada pelatihan Diklat TP I yang dilaksanakan di di Bandung dan Cisolok berdasarkan umpan balik (feedback) peserta. Sejauh mana perbedaan implementasi pelayanan kediklatan yang diberikan di dua lokasi tersebut? Aspek apa yang yang menjadi masalah utama bagi peserta? Penelitian ini menggunakan metoda deskriptif kualitatif menggunakan observasi, telaah dokumen, dan wawancara.

\section{TINJAUAN PUSTAKA}

\section{Pengembangan Kompetensi dan Karir Pegawai}

Sumber Daya Manusia (SDM) merupakan modal terpenting bagi organisasi, yang mana waktu, tenaga, dan kemampuannya dapat dimanfaatkan bagi kepentingan organisasi, Fathoni (2006). Oleh karena itu, pengembangan kompetensi pegawai suatu organisasi menjadi hal yang sangat penting bagi keberlangsungan dan kemajuan organisasi, Siagian (2001).

Hubungan perencanaan karir (pengembangan kompetensi individu) dan manajemen karir bisa dilihat pada Gambar 1. Dimana perencanaan karir adalah suatu proses dimana individu dapat mengidentifikasi dan mengambil langkah-langkah untuk mencapai tujuan karirnya, sedangkan manajemen karir adalah proses dimana organisasi memilih, menilai, menugaskan, dan mengembangkan para pegawainya guna menyediakan SDM yang berkualitas untuk memenuhi kebutuhan organisasi di masa yang akan datang.

Sedangkan menurut Soetjipto dkk (2002), karir merupakan bagian dari perjalanan hidup seseorang, bahkan bagi sebagian orang merupakan suatu tujuan hidup.

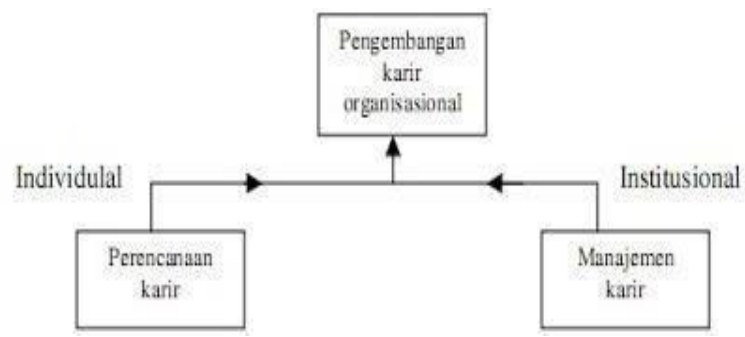

Gambar 1. Pengembangan Karir Organisasional (Simamora, Manajemen Sumber Daya Manusia, 2001)

\section{Pendidikan dan Pelatihan di KESDM}

Pengertian diklat untuk jabatan PNS menurut Peraturan Pemerintah No.101 Tahun 2000 tentang Pendidikan dan Pelatihan Jabatan Pegawai Negeri Sipil, adalah penyelenggaraan belajar mengajar dalam rangka meningkatkan kemampuan Pegawai Negeri Sipil. Ada dua jenis diklat yang diatur dalam peraturan tersebut, yaitu Diklat Prajabatan dan Diklat Dalam Jabatan. Diklat TP I yang akan dibahas pada penulisan ini adalah termasuk ke dalam diklat dalam jabatan yang diselenggarakan oleh PPSDMA. 


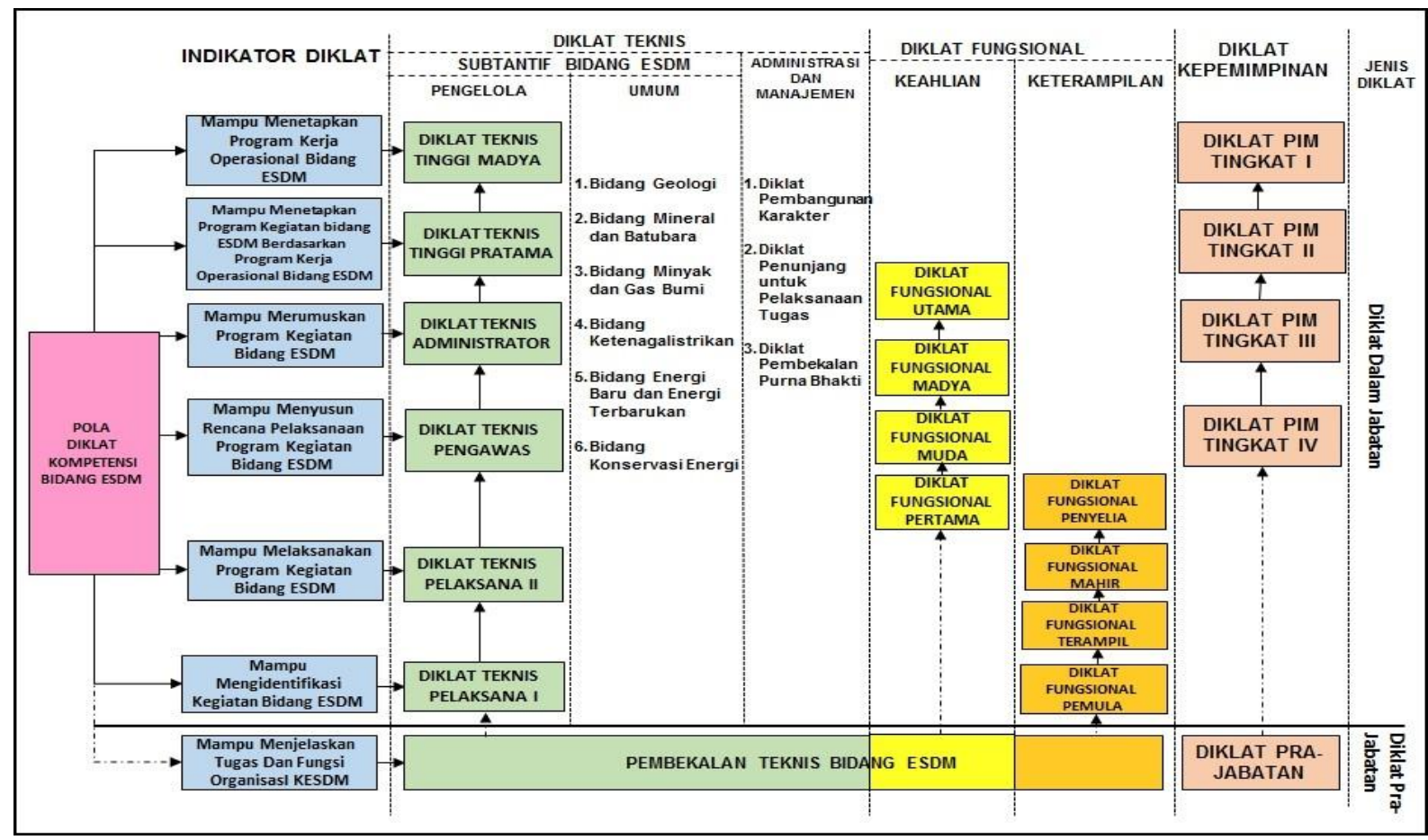

Gambar 2. Skema Diklat bagi PNS Bidang Energi dan Sumber Daya Mineral

Diklat teknis di lingkungan Kementerian ESDM telah diatur di dalam Peraturan Menteri ESDM No. 34 Tahun 2016 tentang Pendidikan dan Pelatihan Teknis Bagi Pegawai Negeri Sipil Bidang Energi dan Sumber Daya Mineral. Dalam Permen KESDM tersebut juga terlampir skema diklat bagi PNS di lingkungan KESDM sebagai acuan untuk pengembangan kompetensi. Skema pengembangan diklat teknis di lingkungan Kementerian ESDM dapat dilihat pada Gambar 2.

\section{Pelayanan dan Evaluasi Penyelenggaraan Diklat}

Standar pelayanan menurut Ratminto dan Winarsih (2015) merupakan ukuran yang dibakukan dalam penyelenggaraan pelayanan publik yang wajib ditaati oleh pemberi atau penerima pelayanan, yaitu: 1). Prosedur pelayanan; 2). Waktu penyelesaian; 3). Biaya pelayanan; 4). Produk pelayanan; 5). Sarana dan prasarana; dan 6). Kompetensi petugas pemberi pelayanan. Tahap evaluasi pada manajemen penyelenggaraan diklat sangatlah penting, karena evaluasi bisa menjadi alat 'controlling' pada keberlangsungan proses diklat. Menurut Antony (2002), analisis organisasi dapat dilakukan untuk menyusun faktor-faktor penting yang dapat memengaruhi efektivitas program pelatihan yang beroperasi dalam konteks organisasi, seperti yang terlihat pada Gambar 3. 


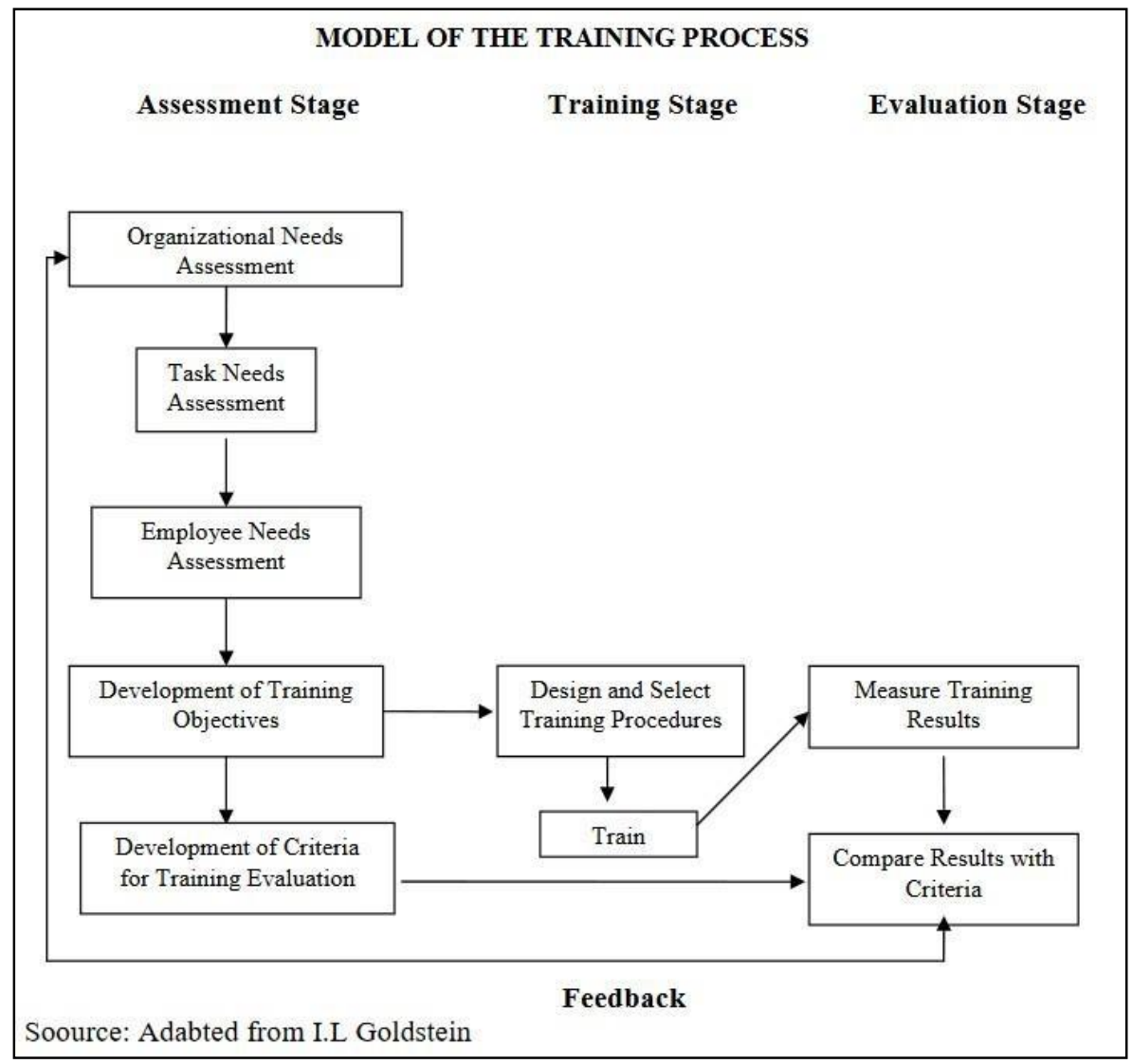

Gambar 3. Model Proses Diklat

\section{HASIL DAN PEMBAHASAN Penyelenggaraan Diklat TP I}

Diklat TP I 2018 diselenggarakan di dua lokasi berbeda dan dibagi menjadi lima belas angkatan dengan total realisasi peserta sebanyak 455 orang (dari target 500 orang), Tabel 1 merupakan gambaran pelaksanaan Diklat TP I 2018 yang dirangkum dari hasil evaluasi penyelenggaraan diklat.Tabel 1). Gambaran tabel ini menunjukan bahwa penyelenggaraan Diklat TP I tahun 2018 tersebut memiliki frekwensi penyelenggaraannya yang padat. Berdasarkan kurikulum yang telah disahkanoleh

BPSDM dengan No. 132 K/60.06/BDL/2016, Diklat TP I memiliki jumlah Jam Pelajaran $81 \mathrm{JP}$ (diluar kegiatan visitasi lapangan sebagai penunjang kegiatan). Waktu efektif penyelenggaraan kurang lebih 10 hari (tidak termasuk hari sabtu-minggu). Berdasarkan waktu pelaksanaan yang padat tersebut, maka persiapan penyelenggaraan pun menjadi sangat terbatas.

Tabel 1. Penyelenggaraan Diklat TP I 2018

\begin{tabular}{|c|c|c|c|c|c|}
\hline \multicolumn{3}{|c|}{ Bandung } & \multicolumn{3}{c|}{ Cisolok } \\
\hline Angkatan & Tanggal & Jumlah Peserta & Angkatan & Tanggal & Jumlah Peserta \\
\hline III & $12-27$ Februari & 39 Orang & I & 22 Januari - 2 & 35 Orang \\
& 2018 & $(20 \mathrm{P}, 19 \mathrm{~W})$ & & Februari 2018 & $(25 \mathrm{P}, 10 \mathrm{~W})$ \\
\hline IV & $3-14$ Juli 2018 & 34 Orang & II & $12-27$ Februari & 32 Orang \\
& & $(13 \mathrm{P}, 21 \mathrm{~W})$ & & 2018 & $(23 \mathrm{P}, 9 \mathrm{~W})$ \\
\hline XIV & $3-15$ & 38 Orang & V & $5-19$ Maret & 36 Orang \\
& September 2018 & $(23 \mathrm{P}, 13 \mathrm{~W})$ & & 2018 & $(23 \mathrm{P}, 13 \mathrm{~W})$ \\
\hline
\end{tabular}




\begin{tabular}{|c|c|c|c|c|c|}
\hline $\begin{array}{c}\text { XV } \\
\text { jar Hern }\end{array}$ & 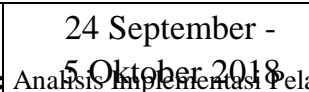 & 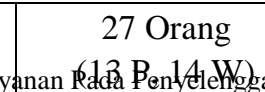 & $\begin{array}{c}\text { VI } \\
\text { niklat di PPSI }\end{array}$ & $\begin{array}{r}26 \mathrm{M} \\
\mathrm{MA} \quad \mathrm{Ap} \\
\end{array}$ & $\begin{array}{c}35 \text { Orang } \\
(21 \mathrm{P}, 14 \mathrm{~W})\end{array}$ \\
\hline
\end{tabular}

Jurnal Aparatur, Volume 3, No. 1, Juli 2019| 17 


\begin{tabular}{|c|c|c|c|c|c|}
\hline \multicolumn{3}{|c|}{ Bandung } & \multicolumn{3}{|c|}{ Cisolok } \\
\hline Angkatan & Tanggal & Jumlah Peserta & Angkatan & Tanggal & Jumlah Peserta \\
\hline & & & VII & $\begin{array}{c}16-30 \text { April } \\
2018\end{array}$ & $\begin{array}{c}33 \text { Orang } \\
(24 \mathrm{P}, 9 \mathrm{~W})\end{array}$ \\
\hline & & & VIII & $2-12$ Juli 2018 & $\begin{array}{c}28 \text { Orang } \\
(19 \mathrm{P}, 9 \mathrm{~W})\end{array}$ \\
\hline & & & IX & $\begin{array}{c}16-26 \text { Juli } \\
2018\end{array}$ & $\begin{array}{c}22 \text { Orang } \\
(15 \mathrm{P}, 7 \mathrm{~W})\end{array}$ \\
\hline & & & $\mathrm{X}$ & $\begin{array}{c}30 \text { Juli - } 9 \\
\text { Agustus } 2018 \\
\end{array}$ & $\begin{array}{c}26 \text { Orang } \\
(22 \mathrm{P}, 4 \mathrm{~W})\end{array}$ \\
\hline & & & $\mathrm{XI}$ & $\begin{array}{c}27 \text { Agustus - } 7 \\
\text { September } 2018\end{array}$ & $\begin{array}{l}27 \text { Orang } \\
(21 \mathrm{P}, 6 \mathrm{~W})\end{array}$ \\
\hline & & & XII & $\begin{array}{c}17-28 \\
\text { September } 2018\end{array}$ & $\begin{array}{c}21 \text { Orang } \\
(17 \mathrm{P}, 4 \mathrm{~W})\end{array}$ \\
\hline & & & XIII & $\begin{array}{c}1-12 \text { Oktober } \\
2018\end{array}$ & $\begin{array}{l}22 \text { Orang } \\
(7 \mathrm{P}, 15 \mathrm{~W})\end{array}$ \\
\hline
\end{tabular}

Lokasi (kampus) lapangan Cisolok berjarak sekitar $160 \mathrm{~km}$ dari Bandung dan dapat dicapai dengan kendaraan roda empat melalui jalur darat dengan waktu tempuh kurang lebih 4-6 jam perjalanan. Di kampus ini tidak ditemukan standar ruang kelas untuk pelatihan. Ruang kelas yang digunakan pada Diklat TP I tahun 2018 adalah aula. Sarana penunjang lainnya sangat terbatas, seperti tidak adanya ruang perpustakaan, ruang gymnasium (olah raga), laboratorium komputer, dan jaringan internet. Selain sarana gedung dan ruang kelas yang kurang memadai, faktor sarana transportasi di kampus lapangan Cisolok menjadi masalah lainnya bagi peserta diklat.

Sedangkan lokasi diklat di Bandung memiliki wisma berkapasitas 60 orang; 8 ruang kelas, 1 perpustakaan, 1 laboratorium komputer. Selain itu sarana penunjang lainnya, seperti mushola, ruang makan dan ruang olah raga juga tersedia.

\section{Analisis Temuan}

Berdasarkan dokumen hasil evaluasi pemantauan penyelenggaraan pada Diklat TP I tahun 2018 sebanyak 15 angkatan, penulis mencoba merangkum perbandingan hasil evaluasi tersebut. Penulis membandingkan tanggal pelaksaan diklat, jumlah peserta diklat (pria dan wanita), jumlah saran yang diberikan peserta, dan hasil Survey Kepuasan Masyarakat (SKM). Tabel lengkap perbandingan hasil evaluasi ada dalam lampiran.

Berdasar Tabel 1, penulis menampilkan data temuan kedalam bentuk grafik agar lebih mudah untuk dianalisa. Grafik-grafik tersebut membandingkan Diklat TP I berdasarkan jumlah peserta diklat per angkatan; berdasarkan peserta pria per angkatan; berdasarkan peserta wanita per angkatan dan berdasarkan saran yang diterima dari peserta per angkatan.

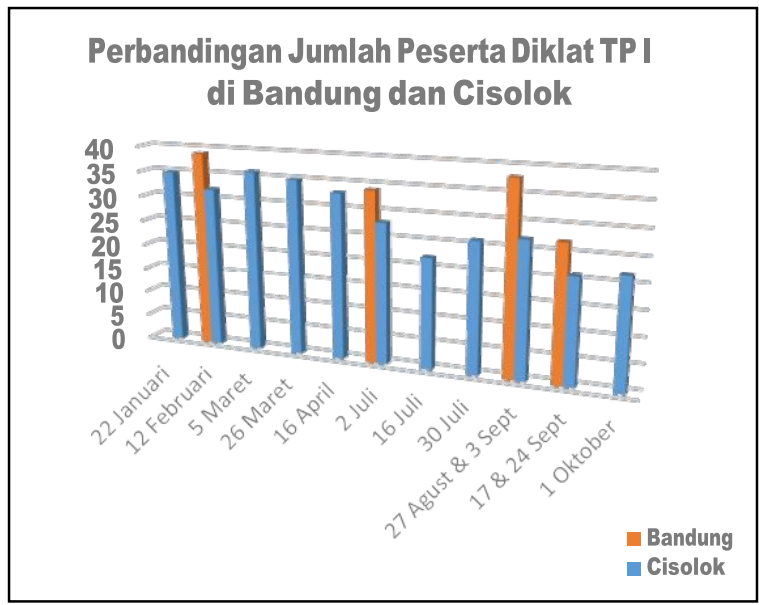

Gambar 4.

Perbandingan Jumlah Peserta Diklat TP I

Berdasarkan Gambar 4, terlihat bahwa ada perbedaan jumlah peserta pada Diklat TP I yang diselenggarakan di Bandung dan Cisolok, dimana selalu lebih banyak dibandingkan dengan Cisolok. Baik itu pada tangga pelaksanaan yang bersamaan (12 Februari dan 2 Juli), begitu juga pada pelaksanaan yang mempunyai jeda satu minggu (27 Agustus dan 3 September; 17 dan 24 September), terlihat hal yang sama, yaitu peserta yang lebih banyak ada pada Diklat TP I yang diselenggarakan di Bandung. Hal ini 
menunjukkan bahwa peserta lebih memilih/senang untuk mengikuti diklat yang dilaksanakan di Bandung dibandingkan Cisolok, karena biasanya peserta akan mencari tahu kondisi Cisolok seperti apa dan membandingkannya dengan kondisi diBandung. Penyebab tidak ikutnya peserta bisa beraneka ragam, bisa karena peserta memang berhalangan hadir karena ada tugas lain; peserta belum mengenal daerah Cisolok; atau peserta telah mengenal/menerima informasi tentang kondisi Cisolok itu sendiri.

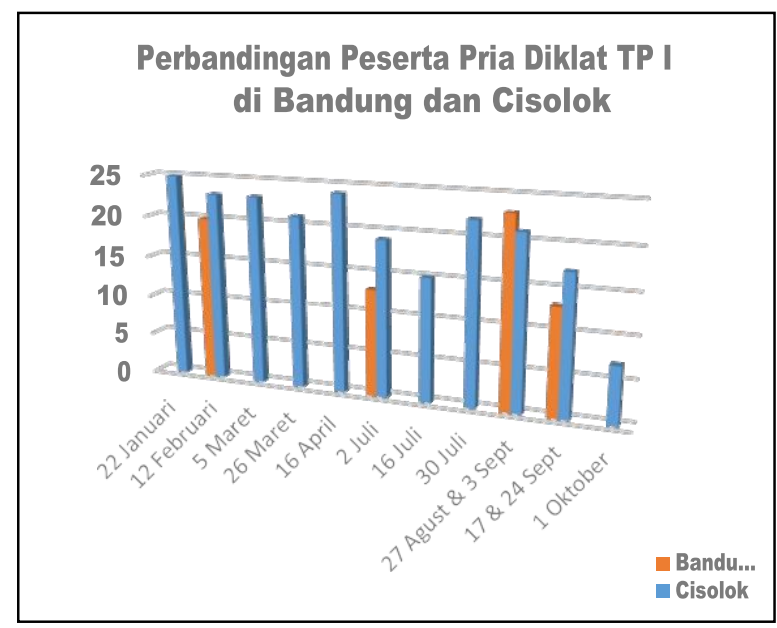

Gambar 5.

Perbandingan Peserta Pria pada Diklat TP I

Gambar 5 menggambarkan tentang perbandingan peserta pria pada penyelenggaraan Diklat TP I di Bandung dan Cisolok. Terlihat bahwa jumlah peserta pria yang mengikuti diklat di Cisolok selalu lebih banyak dibandingkan dengan di Bandung, hanya pada Angkatan XI saja peserta pria yang ikut diklat di Cisoloklebih sedikit dibandingkan dengan Angkatan II, VIII, dan VII yang diselenggarakan di Bandung. Hal ini sangat wajar, karena peserta pria sebenarnya tidak begitu terpengaruh dengan lokasi tempat dimana diklat tersebut diselenggarakan. Karena peserta pria cenderung bisa menerima dan mudah beratapsi dengan kondisi dan lingkungan tempat diklat berlangsung. Peserta pria mempunyaijiwa petualang yang tinggi, sehingga ketika mengikuti pelatihan yang diselenggarakan di Cisolok, mereka dapat menikmati kondisi Cisolok dan selalu berinisisasi untuk melakukan petualanganpetualangan yang seru selama pelatihan berlangsung.

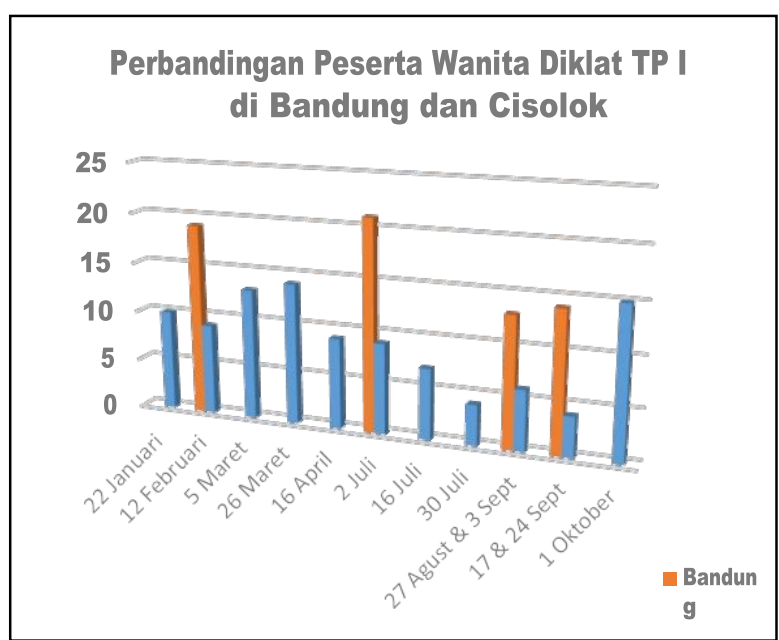

Gambar 6. Perbandingan Peserta Wanita pada Diklat TP I

Gambar 6 menggambarkan kondisi sebaliknya dari gambar sebelumnya, terlihat bahwa perbandingan jumlah peserta wanita pada Diklat TP I yang diselenggarakan di Bandung selalu lebih banyak dibandingkan dengan Cisolok, hanya pada pelaksanaan terakhir saja (Angkatan XIII) yang jumlah peserta wanitanya terbanyak di Cisolok. Hal ini sangat wajar sekali, karena peserta wanita cenderung lebih senang untuk mengikuti diklat di Bandung yang berada di pusat kota dan lebih dekat dengan segala fasilitasnya. Bahkan terlihat jelas pada penyelenggaraan diklat pada tanggal 16 April jumlah peserta wanita turun secara signifikan. Hal ini tidak terlepas dari perubahan kurikulum dengan adanya penambahan materi kedisiplinan (Bintalsik) yang melibatkan Kopassus dan Koramil pada pelaksnaan diklat sebelumnya (26 Maret). Sejak ditambahkannya materi Bintalsik tersebut, terlihat terjadi penurunan jumlah peserta wanita setiap bulannya sampai akhirnya peserta wanita terakumulasi pada penyelenggaraan diklat terakhir (1 Oktober).

Pengaruh dari perubahan kurikulum (materi kedisiplinan/Bintalsik) tersebut memang mempunyai dampak yang signifikan. Dampak positif dari bintalsik adalah peserta menjadi lebih disiplin dan lebih semangat dalam mengikuti diklat, walaupun pada awal pelaksanaannya peserta merasa kecewa dan tidak nyaman dengan adanya materi tersebut. Kekecewaan peserta diklat terlihat dalam lembar evaluasi yang dibagikan kepada peserta, banyak saran yang disampaikan oleh peserta mengenai penyelenggaraan diklat termasuk mengenai penambahan materi 
Bintalsik yang pertama kali diterapkan dalam diklat (Angkatan VI, 26 Maret), dengan jumlah 53 saran dari 35 peserta. Hal tersebut terlihat pada Gambar 7 yang menunjukkanperbandingan dari saran yang disampaikan peserta pada Diklat TP I. Berikut adalah contoh saran dari salah satu peserta tentang adanya kegiatan Bintalsik: "Kegiatan dengan kopasus sejatinya sangat disarankan, mengingat hal tersebut memberikan dampak positif terhadap semangat belajar peserta. Namun karena fasilitas yang kurang, jadi ada beberapa kegiatan yang tidak dapat dilakukan. Selanjutnya disarankan kegiatan dengan kopasus dilakukan di pusdikpasus agar fasilitas kesehatan peserta pun lebih terjamin". Dari grafik tersebut juga terlihat bahwa saran terbanyak adalah pada Diklat TP I yang diselenggarakan di Cisolok dibandingkan di Bandung. Hal ini menunjukkan adanya kekurangan pelayanan kediklatan yang terdapat di Cisolok.

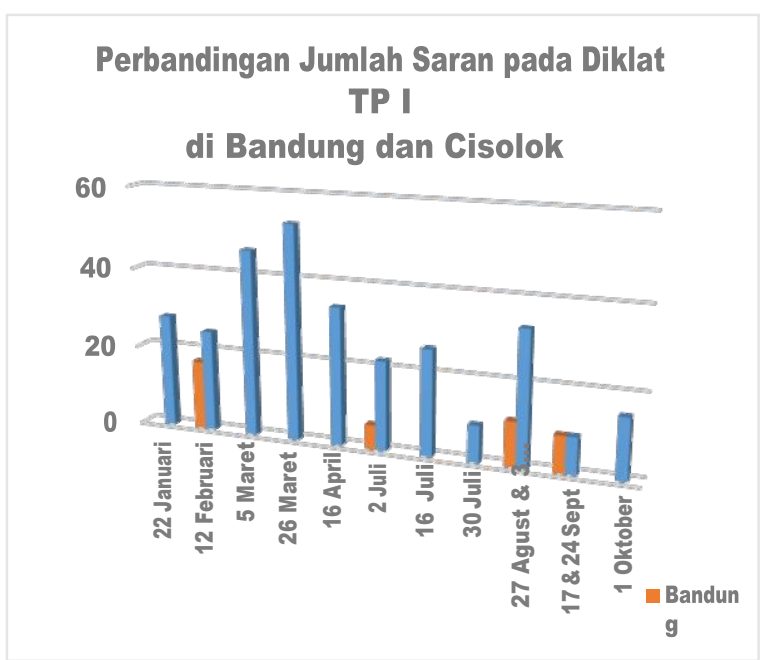

Gambar 7. Perbandingan Saran Peserta pada Diklat TP I

\section{Hasil Wawancara}

Wawancara dilakukan kepada salah seorang panitia yang terlibat dalam penyelenggaraan Diklat TP I tahun 2018. Sesi wawancara dilakukan pada tanggal 28 Januari 2019, dengan metode informan mengisi lembar wawancara yang telah dilengkapi dengan 6 (enam) pertanyaan tentang penyelenggaraan Diklat TP I di Bandung dan Cisolok. Wawancara berlangsung dengan baik dan lancar.

Hasil wawancara yang diperoleh dari informan, pada dasarnya sama dengan hasil penelitian yang dilakukan pada dokumen hasil evaluasi pemantauan penyelenggaraan diklat. Informan memberikan pandangannya tentang pelaksanaan diklat yang secara umum terlaksana dengan baik. Informan juga berpendapat bahwa pelayanan kediklatan harus sama antara Bandung dan Cisolok. Kekurangan fasilitas dan sarana prasarana di kampus lapangan Cisolok menjadi poin yang penting menurut informan. Komunikasi dan kebersamaan yang terbangun antar peserta maupun dengan panitia selama pelaksanaan diklat di Cisolok menjadi kelebihannya. Hasil wawancara lengkap dengan informan terdapat di lampiran.

\section{PENUTUP \\ Kesimpulan}

Kesimpulan penelitian tentang implementasi pelayanan kediklatan pada Diklat TP I yang diselenggarakan di Bandung dan Cisolok adalah sebagai berikut:

1. Penyelenggaraann Diklat TP I tahun 2018 di Bandung dan Cisolok secara administratif dan substantif telah terlaksana dengan baik, dengan menghasilkan 15 angkatan dan 455 orang lulusan peserta diklat. Namun secara teknis, implementasi pelayanan kediklatan pada Diklat TP I belum dapat dijalankan dengan optimal oleh penyelenggara diklat, hal tersebut dikarenakan keterbatasan sarana prasarana dan fasilitas penunjang di Cisolok yang membedakan pelaksanaannya dengan di Bandung.

2. Perubahan kebijakan diklat yang dalam hal ini perubahan kurikulum, sangat berpengaruh kepada proses penyelenggaraan pelatihan dan berdampak langsung kepada peserta pelatihan, dengan dibuktikan adanya komentar bernada kekecewaan dan berimbas kepada komentar-komentar lainnya selama penyelenggaraan diklat.

3. Perbedaan lokasi, sarana prasarana dan fasilitas penunjang kediklatan sangat berpengaruh pada Diklat TP I ini, khususnya terhadap peserta wanita.

4. Keberadaan kampus lapangan Cisolok masih diperlukan dengan syarat perlu adanya standarisasi kelengkapan dan layanan Diklat TP I yang diselenggarakan di Bandung dan Cisolok agar output yang dihasilkan sama.

\section{Rekomendasi}

Usulan rekomendasi yang diusulkan dalam penulisan ini adalah sebagai berikut: 
1. Adanya perencanaan yang matang jika akan meyelenggarakan pelatihan di dua tempat yang berbeda secara bersamaan. Manajemen kediklatan harus dikaji secara komprehensif dan terintegritas, mencakup sarana prasarana dan fasilitas penunjang lainnya. Tidak hanya menerima/menyanggupi target organisasi tanpa perencanaan yang baik

2. Perlunya dibuat standar pelayanan kediklatan yang baik dan di sosialisasikan kepada semua stakeholder, baik internal maupun eksternal.

3. Jika terjadi perubahan pada kebijakan diklat maupun pelayanan kediklatan, hendaknya disosialisasikan dengan segera agar tidak terjadi mis-informasi dan mis-komunikasi antara penyelenggara dengan peserta diklat.

\section{DAFTAR PUSTAKA}

Antony, William P. (2002). Human Resouces Management, A Strategic Approach, United States Of America. ${ }^{125}$

Arikunto, Suharsimi \& Safruddin, Cepi (2004). Evaluasi Program Pendidikan Pedoman Teoritis Praktis Bagi Mahasiswa dan Praktisi Pendidikan. Bumi Aksara, Jakarta. $^{3}$

Cascio, Wayne F. (2016). Managing Human Resources; Productivity, Quality of Work Life, Profits, Tenth Edition, McGraw Hill Education. ${ }^{379}$

Fathoni, Abdurrahmat (2006). Organisasi dan Manajemen Sumber Daya Manusia. Rineka Cipta, Jakarta. ${ }^{8}$

Marwansyah (2010). Manajemen sumber daya manusia. Alfabeta, Bandung. ${ }^{154}$

Moeheriono (2010). Pengukuran Kinerja Berbasis Kompetensi. GhaliaIndonesia, Bogor. ${ }^{3,4}$

Peraturan Pemerintah No. 101 Tahun 2000 tentang Pendidikan dan Pelatihan Jabatan Pegawai Negeri Sipil

Peraturan Menteri Energi dan Sumber Daya Mineral No. 34 Tahun 2016 tentang Pendidikan dan Pelatihan Teknis Bagi Pegawai Negeri Sipil Bidang Energi dan Sumber Daya Mineral

Ratminto \& Winarsih, Atik S. (2015). Manajemen Pelayanan. Pustaka Pelajar, Yogyakarta. ${ }^{18,22,23}$

Siagian, Sondang P. (2001). Manajemen Sumber Daya Manusia. Bumi Aksara, Jakarta. ${ }^{182}$

Soetjipto, Budi W., dkk. (2002). Paradigma Baru Manajemen Sumber Daya Manusia. Amara Books, Yogyakarta. ${ }^{276}$ Simamora, Henry (2001). Manajemen Sumber Daya Manusia, Edisi 2. Penerbit STIE YKPN, Yogyakarta. $^{505}$

Undang-Undang No. 5 Tahun 2014 tentang Aparatur Sipil Negara
LAMPIRAN

FORM WAWANCARA

I. Informasi Wawancara

$\begin{array}{ll}\text { Tanggal } & : 28 \text { Januari } 2019 \\ \text { Tempat } & : \text { Randung }\end{array}$

II. Identitas Informan

Nama Lengkap: Ega Nugraha

Umur

40

Jenis Kelamin : Lak-Laki

Pendidkan : D-3

Jabatan Pengdah Data

Instansi PPSDM Aparahur KESDM

III. Daftar Pertanyaan

1. Bagaimana pendapat Saudara secara umum tentang penyelenggaraan Diklat TP I tersebut?

2. Bagaimana pendapat Saudara tentang penyelenggaraan Diklat TP I di dua lokasi, Bandung dan Cisolok, Sukabumi? Apakah Saudara terlibat dalam penyelenggaraan ci kedua lokasi tersebut?

3. Menurut penilaian Saudara, apakah standar pelayanan dalam penyelenggaraan diklat yang diberikan pada Diklat TP I di Bandung sama dengan di Cisolok? Mohon berikan penjelasan?

4. Menurut Saudara, apa saja kelebihan dan kekurangan penyelenggaraan Diklat TP I di masing-masing lokasi tersebut?

5. Apakah Saudara berinteraksi langsung dengan peserta diklat? Jika "Ya", apa yang Saudara ketahui terkat tanggapan peserta diklat mengenai penyelenggaraan diklat di kedua lokasi tersebut?

6. Bagaimana kesan Saudara setelah teribat di dalam penyelenggaraan Diklat TP I di kedua lokasi tersebut? Adakah saran yang ingin disampaikan terkait penyelenggaraan Diklat TP I ini?

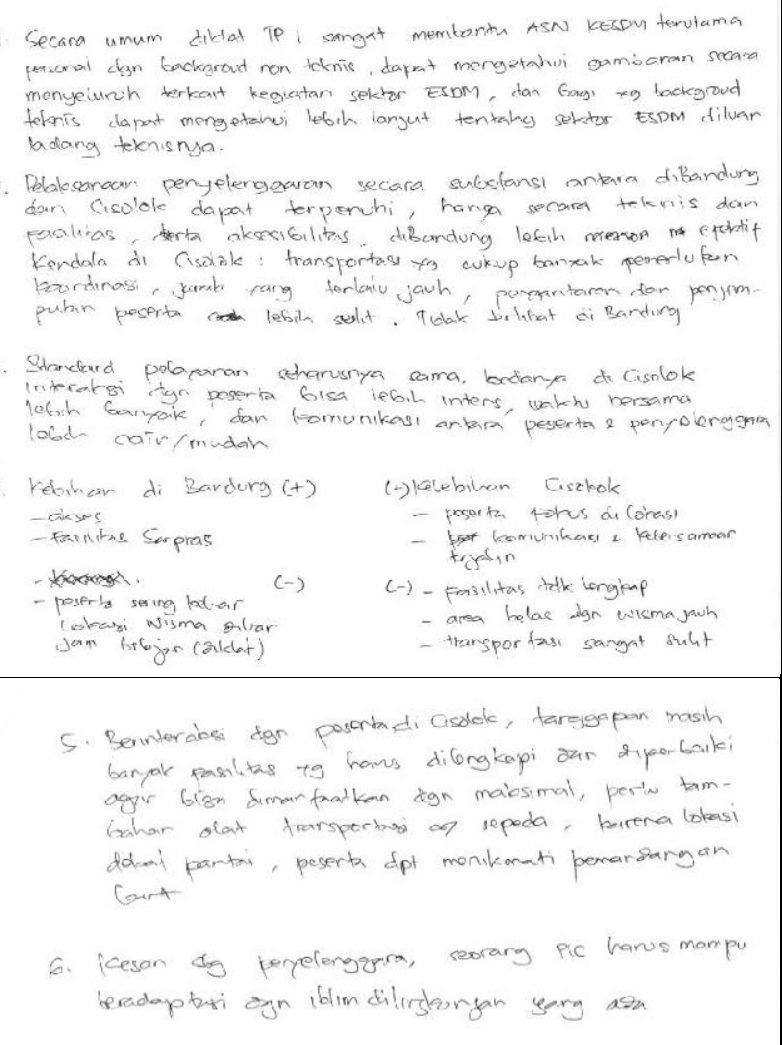

Secara umum diblat TP, sangat membarita ASN kESOM terutama

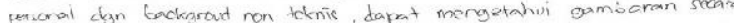

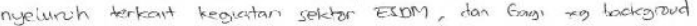

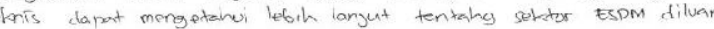

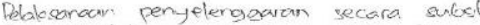

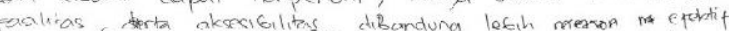
Eendala di Cisolak: transportass on wikup banzak pemertufor

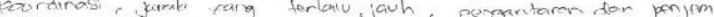

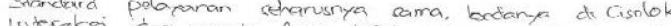

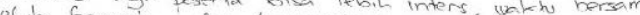
Kebihaar di Bardurg (t) (t) Gutebilwan Ciszlook

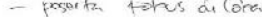

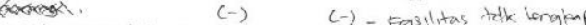
Core holas ign wicma jawh jam brbion (alcbat) - transportasi sangat suht

taregapan masih doans dibngkapi azan 2yer Gaik egr maksmal pertu tam-

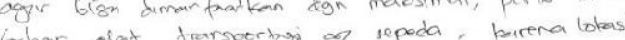
dd.ai pantai peserb for monikonati bemardargan icesan dig perjelenggra, seorarg PiC harus mampo

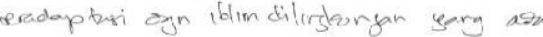

